\title{
Probabilistic Forecasts for Energy: Weeks to a Century or More
}

\author{
John A. Dutton, Richard P. James, and Jeremy D. Ross
}

Abstract Quality of service and fiscal success in the energy industry often depend on how well meteorological information and forecasts are used to manage risk and opportunity. On the subseasonal to seasonal (S2S) timescales, a disciplined strategy allows decision makers to counteract predicted adverse climate variations in the coming weeks or months with action or financial hedges. Calibrated S2S probabilistic forecasts from some providers have sufficient skill that they engender confidence in the statistical consequences of acting. On the scale of several or more decades ahead, probabilistic outlooks can guide strategic planning and capital expenditures in directions that will ensure long-term resilience to climate change. In both cases, the probabilities are generated by statistical analysis of ensembles of supercomputer forecasts or climate change scenarios.

Keywords Probabilistic forecasts - Subseasonal and seasonal climate prediction $\bullet$ Climate change $\bullet$ Resilience $\bullet$ Energy industry

J.A. Dutton $(\bowtie) \bullet$ R.P. James $\bullet$ J.D. Ross

Prescient Weather Ltd, State College, PA, USA

(C) The Author(s) 2018

A. Troccoli (ed.), Weather \& Climate Services for the Energy Industry, https://doi.org/10.1007/978-3-319-68418-5_12 


\section{INTRODUCTION}

The energy industry has a voracious appetite for meteorological information on many time and space scales, and both the quality of service and fiscal performance depend on how well the information is used to manage risk and take advantage of opportunity. Today the various components of the industry can combine probabilistic information with sophisticated decision methods to produce predictable and desirable statistical results (Dutton et al. 2013, 2014).

On the subseasonal to seasonal (S2S) timescale, a disciplined strategy allows decision makers to counteract likely adverse events in the coming weeks or seasons with action or financial hedges. On the scale of several or more decades ahead, probabilistic outlooks can guide strategic planning and capital expenditure in directions that will ensure long-term resilience to climate change.

The most useful S2S forecasts and climate change outlooks are probability distributions created from evolving ensembles of forecasts generated by supercomputers calculating tens of forecasts simultaneously by perturbing initial conditions, model characteristics, or boundary conditions. The predicted probability distributions allow decision makers to distinguish between likely and unlikely conditions or events and to respond appropriately.

Indeed, the predicted probability distributions are analogues of the frequency distributions that are used to describe the climatological averages and volatility of energy-critical variables such as temperature. As illustrated by Fig. 12.1, the predicted distributions can show that significant departure from climatological conditions is expected and that action may be warranted.

\section{Subseasonal and Seasonal Climate Prediction}

S2S forecasts ${ }^{1}$ covering weeks to three or six months do not themselves produce benefits in the energy industry or in other activities. Making them useful requires a process to convert forecasts into actionable information and to estimate the consequences of acting on the forecasts. A National Research Council report (NRC 2016) offers a research agenda to improve S2S forecasts.

The energy industry seeks forecasts of future events on S2S timescales in order to minimize adverse results or take advantage of opportunity. For 


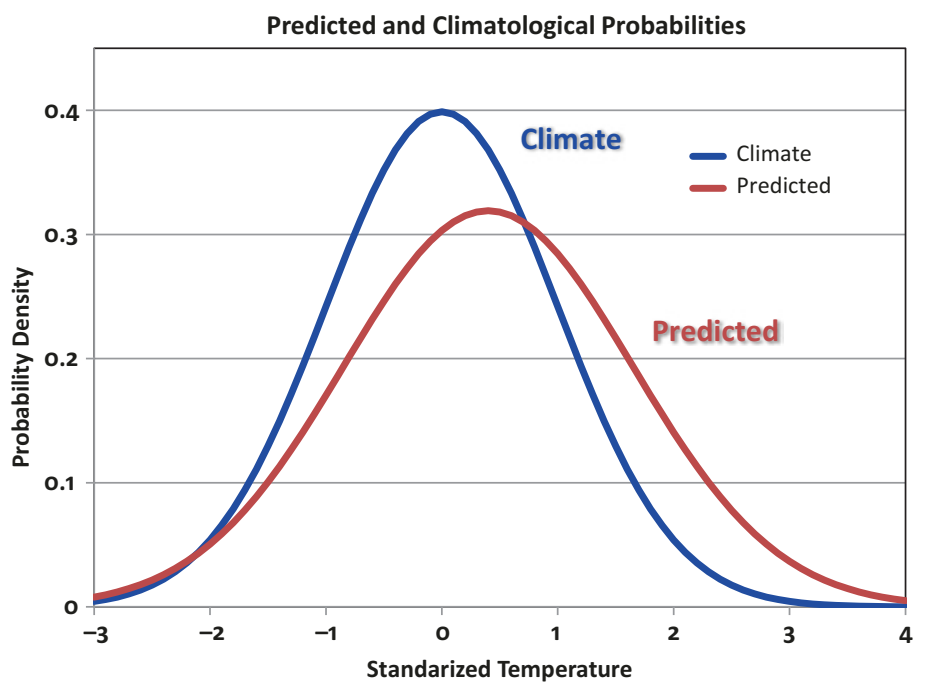

Fig. 12.1 Comparison of predicted and climatological standardized temperatures for a S2S forecast. The area between the climate and predicted densities represents the probability of temperatures warmer than those expected from climate, which would be adverse for winter for an electric utility

example, electric utilities usually consider warm winter temperatures and cool summer temperatures as adverse because income may not meet expectations and thus they may attempt to ensure financial stability with hedges. The possible future states considered in S2S temperature and other forecasts are often divided into three categories: below normal, nearly normal, and above normal, each of frequency one-third in the historical record for each location and time period. S2S forecasts usually provide a predicted probability for each of the three terciles.

The key question users often ask is: At what predicted probability should I act? The better question is: What consequences can I expect if I act at a predicted probability equal to $p$ ? The critical resource for bridging the gap between forecasts and decisions to act is a reliable description of the performance of the forecast system. Then it becomes possible to link statistical summaries of the consequences to various values of predicted probabilities and to answer the question about consequences of action. Figure 12.2 provides a description of such a forecast system. 


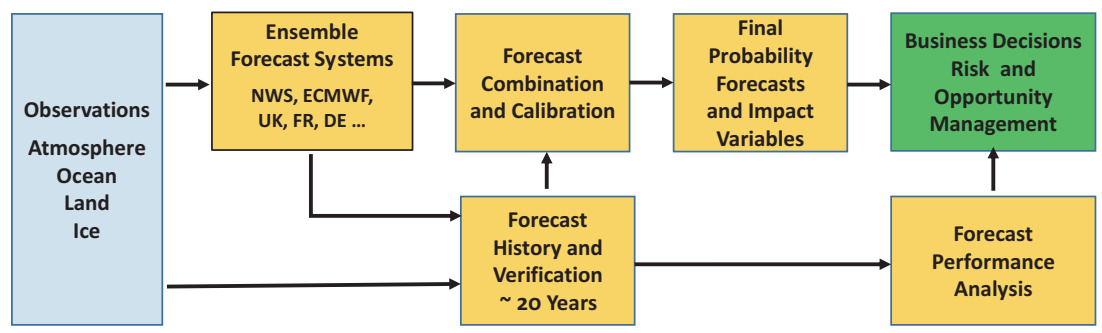

Fig. 12.2 A S2S forecast system that uses the forecast history and verification data to optimize new forecasts in a calibration and combination process. The same data leads to forecast performance statistics that inform the business decisions

Table 12.1 The business model for computing the consequences of forecasts and hedges

\begin{tabular}{lccc}
\hline & & \multicolumn{2}{c}{ Events } \\
& & Adverse & Favorable \\
\hline $\begin{array}{l}\text { Fore- } \\
\text { casts }\end{array}$ & Adverse & $R_{a}+H-C(H)$ & $R_{f}-C(H)$ \\
& Favorable & $R_{a}$ & $R_{f}$ \\
\hline
\end{tabular}

Separating the range of predicted variables into two classes-adverse and favourable-simplifies and illuminates the interaction of forecast performance and business decisions. Let us consider returns $R_{f}$ for favourable conditions and $R_{a}$ for adverse with a loss $L$ being the difference. We consider a hedge for predicted adverse conditions that pays $H$ if they prevail and costs $C(H)$ to establish. Then the contingency table that describes the four possibilities is shown in Table 12.1.

Now we turn to the forecast performance statistics to compute the probabilities of occurrence of each possibility when the adverse case is predicted with probability equal to or greater than $p$.

We divide the range $[0,1]$ of predicted probabilities into 10 bins with centres at $0.05,0.15, \ldots 0.95$ and from the history of forecasts and verification we count for each bin the numbers $V(p)$ and $X(p)$ of correct and incorrect adverse forecasts with a forecast for adverse considered correct if the subsequent observed verification value is in the adverse range. The 


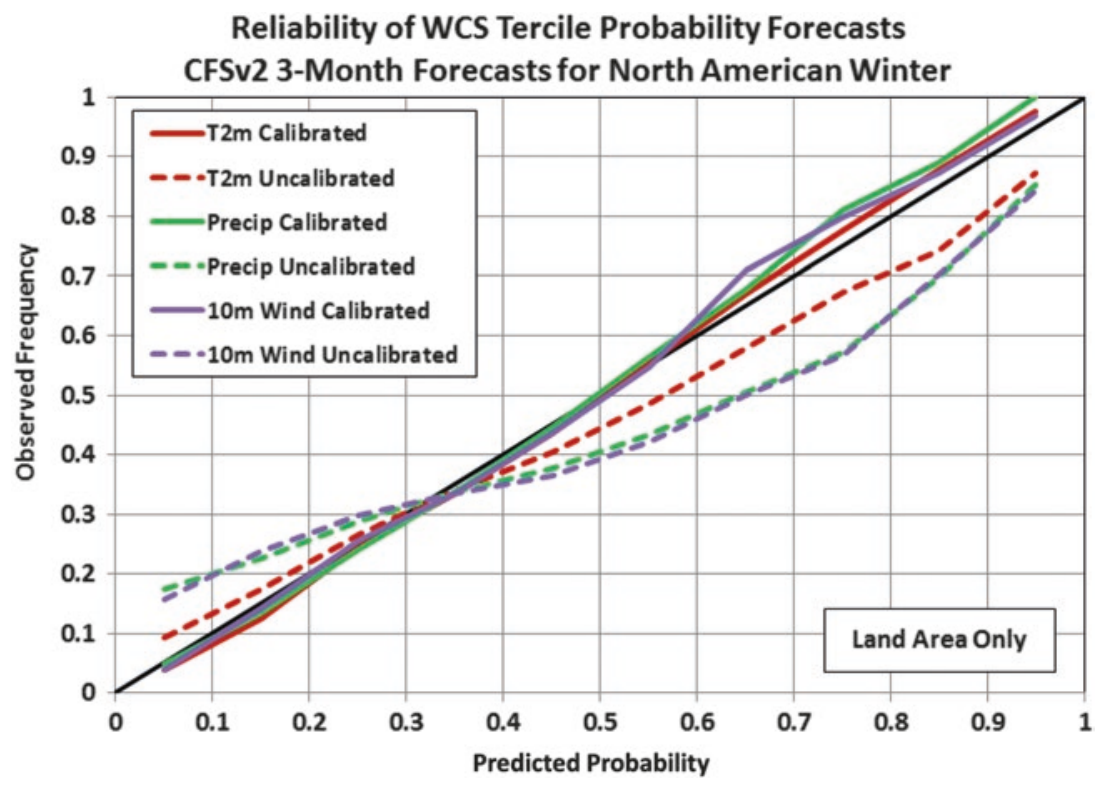

Fig. 12.3 A reliability diagram for WCS forecasts of temperature, precipitation, and wind speed for the North American winter, illustrating the improvement in reliability achieved by calibration. The data for above and below normal have been combined to create a single curve for each variable and thereby simplify the diagram

total number of forecasts $S(p)=V(p)+X(p)$ in each bin is known as the sharpness of the forecasts. We divide these three quantities by the total number $N$ of forecasts and then have the corresponding ratios $p(p), x(p)$, and $s(p)$. The reliability is defined to be $r(p)=p(p) / s(p)$ and thus is a ratio of the number of correct forecasts to the total number of forecasts and is an important indicator of forecast performance. ${ }^{2}$ Figure 12.3 shows a reliability diagram for a set of World Climate Service (WCS) forecasts. ${ }^{3}$

To describe expected outcomes for action at all predicted probabilities $p_{p} \geq p$, we sum over this range and so the fraction $f_{a}(p)$ of adverse forecasts and the fraction $F_{a}(p)$ of correct forecasts are:

$$
f_{a}(p)=\sum_{y \geq p} s(y), F_{a}(p)=\left(\sum_{y \geq p} v(y)\right) / f(p)
$$


and we use these two quantities along with the climatological frequency $n_{a}$ of adverse events to complete the contingency Table 12.2, which contains the probabilities associated with the events in Table 12.1.

The fraction of adverse forecasts at predicted probabilities $p_{p} \geq p$ is $f(p)$ and thus appears as the Sum of the Adverse row. The fraction of correct adverse forecasts is the product $f(p) F(p)$ and appears in the Adverse $\times$ Adverse matrix element. The climatological fraction of adverse events $n_{a}$ appears as the Sum of Adverse events and since we have divided by the total number of forecasts the Sum $\times$ Sum matrix element is 1 . With these four values in place, the rest of the table is completed by simple algebra.

Now we can describe the business results expected by acting on a forecast of adverse conditions. Define the $2 \times 2$ matrix in Table 12.1 shaded yellow as the business model $M$ and its companion in Table 12.2 as the probability matrix $P$. Then with the definition of term-by-term summation as

$$
A \circ B=\sum_{i=1}^{2} \sum_{j=1}^{2} A_{i, j} B_{i, j}
$$

we can compute the expected revenue $R(p)$ and its variance $V(p)$ obtained when acting on $p_{p} \geq p$ as

$$
R=P \circ M, \quad V=P \circ M^{2}-R^{2}
$$

in which the elements of $M^{2}$ are the squared elements of $M$. Here $R$ and $V$ are functions of the variables in Table 12.1 and of the predicted probability $p$ via the functions in Table 12.2.

To obtain quantitative estimates, we must have suitable representations of the forecast performance functions $f_{a}(p)$ and $F_{a}(p)$, as illustrated in Fig. 12.4 for WCS forecasts of temperature, precipitation, and wind for the North American winter. The computations of expected return and variance are simplified by modelling the summands in (12.1) with beta functions, converting the sums in (12.1) to integrals and performing the integration, and thereby obtaining analytical expressions for $f_{a}(p)$ and $F_{a}(p)$.

To complete the analysis, we need estimates of the cost of various hedges. For hedges that pay when the observed verification value falls 
PROBABILISTIC FORECASTS FOR ENERGY: WEEKS TO A CENTURY OR MORE 167

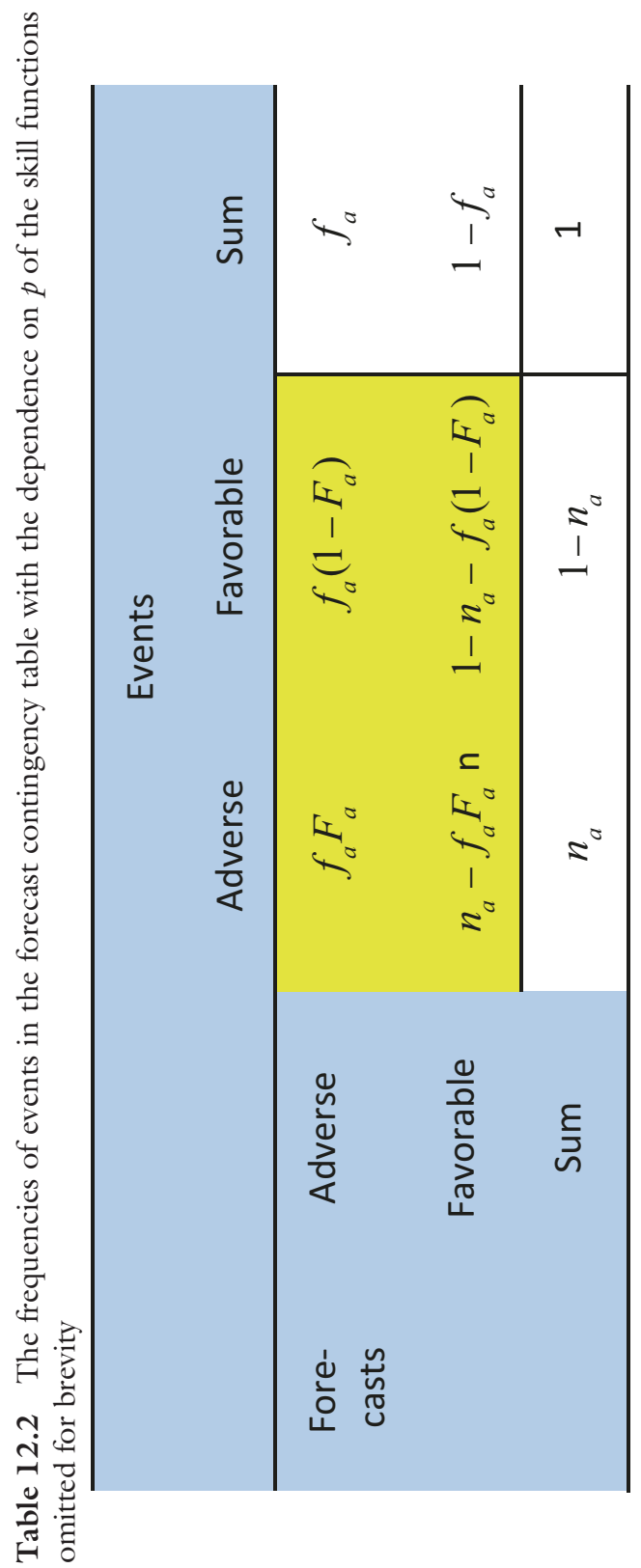




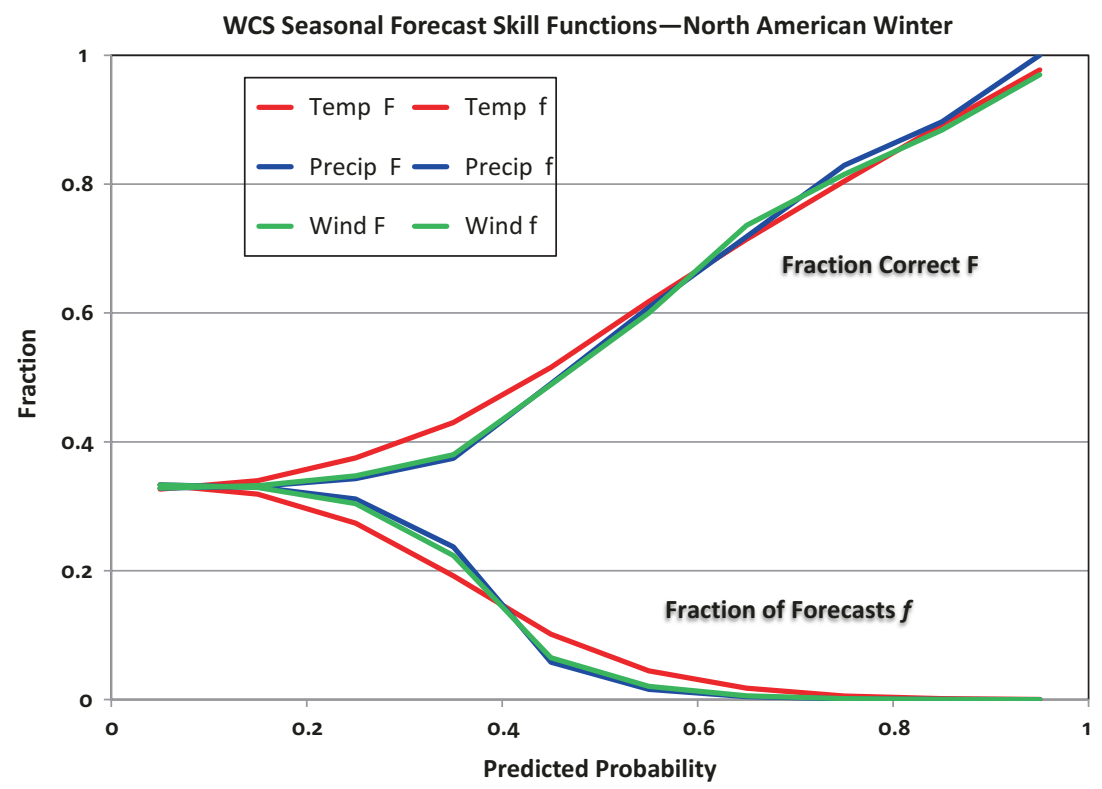

Fig. 12.4 Forecast performance functions for WCS forecasts for temperature, precipitation, and wind for the North American winter

anywhere in the adverse tercile, some sellers use $C(H)=\bar{H}+\eta \sigma_{H}$ with $\bar{H}=n_{a} H$ and $\sigma_{H}^{2}=n_{a} H^{2}-\bar{H}^{2}=n_{a}\left(1-n_{a}\right) H^{2}$ and often select $\eta=1 / 4$.

For example, the WCS maintains and displays detailed information about the skill and reliability of its $S 2 S$ forecasts relative to the terciles (Dutton et al. 2013; James et al. 2014). Now the WCS is combining forecast performance records with a model of the hedging process to create a hedge advisor, shown in Fig. 12.5, that provides expected returns and volatilities for hedges put in place at various predicted probabilities of adverse conditions (Dutton et al. 2015). The return $R(H, p, \ldots)$ and the volatility $\sqrt{V(H, p, \ldots)}$ (standard deviation) are plotted parametrically as functions of $H$ for various values of predicted probability $p$ for warm North American winters with $R_{f}=100$ (units arbitrary) and $L=33$.

These plots thus take explicit account of the historical skill of the forecasts, and thus both buyers and sellers of hedges can act with some confidence about results expected over a number of cases. 


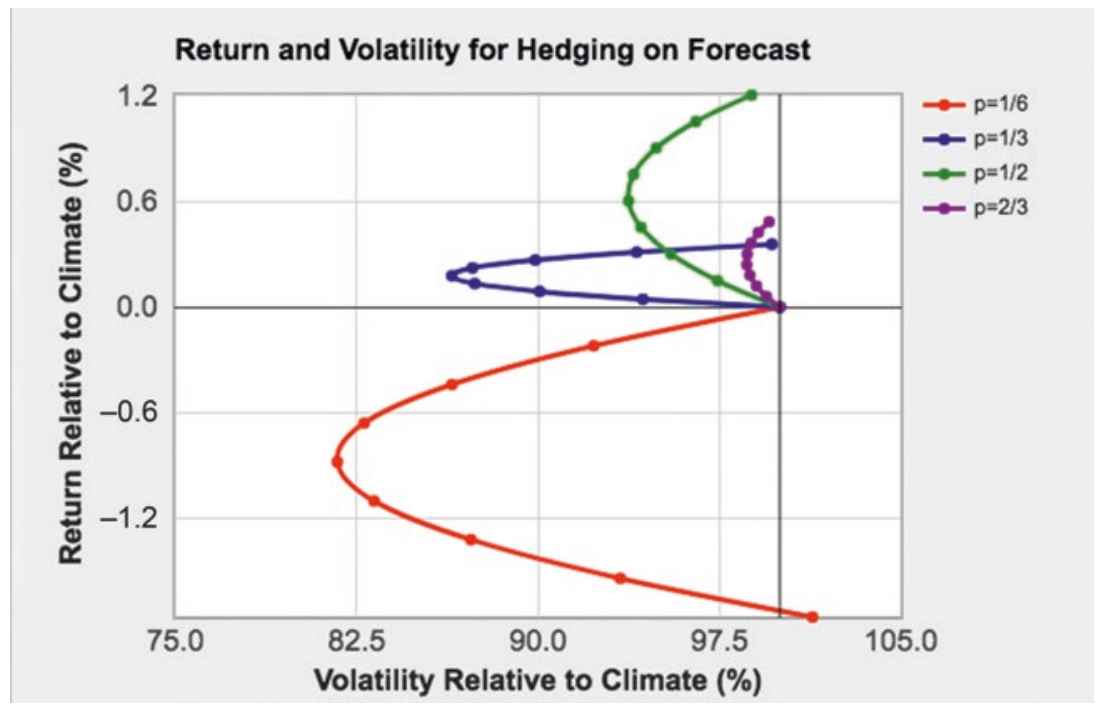

Fig. 12.5 The WCS hedge advisor compares volatility and return for several predicted probabilities of adverse events to those expected from the climatological frequency of the same event. The dots indicate hedges at increments of onequarter of the loss in adverse conditions. The minimum volatility occurs for hedges close to that loss. In this illustration, the skill of the forecasts puts the seller of hedges using $\eta=1 / 4$ at a financial disadvantage for predicted probabilities of $1 / 3$ or greater

As another example, Vitart (2014) provides a summary of the skill of the S2S forecasts of the European Centre for Medium-Range Weather Forecasts (ECMWF). The WCS combines and calibrates these ECMWF forecasts with the S2S forecasts of the US National Weather Service (NWS) to form the multi-model forecasts and performance statistics discussed above. The calibration compares some three decades of retrospective forecasts for previous years with the corresponding verification to develop statistical methods for improving the current forecasts.

\section{Climate Change Probabilities}

Simulations of twenty-first century climate change on the scale of decades or more in the future provide users with an entirely different challenge related to long-term business strategy and capital investment. On this 


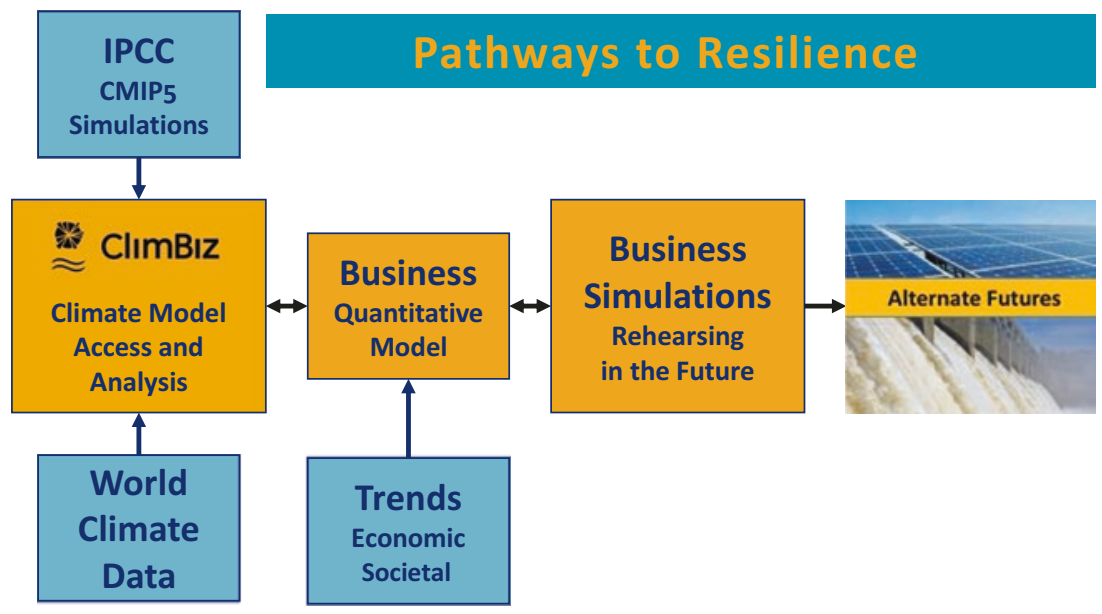

Fig. 12.6 A climate change information system designed to assist business to explore alternative futures, including a system to assemble past and future climate information, a quantitative model of the business, and a system for computing business simulations

scale, uncertainty prevails in all aspects of the energy industry, including environmental variables involved in creating demand and generating power, in technological advance, in prices of fuel or equipment, in the changing numbers and needs of the customers, and in evolving regulation in response to awareness of climate change.

A comprehensive strategy for addressing this challenge is illustrated in Fig. 12.6 which shows how data about observed and future climate can be combined with a quantitative business model to generate simulations of future performance. ${ }^{4}$ The strategy has three components: a source of information about past and future climates, a quantitative business model, and a set of business simulations.

For future climate information, we presently use the climate simulations of 16 national and international modelling centres prepared for the Climate Model Intercomparison Project 5 (CMIP5) (Taylor et al. 2012) for the fifth report of the Intergovernmental Panel on Climate Change (IPCC 2013). Using these simulations, we can create probability distributions for environmental variables that depict climate evolution and variation as forced by greenhouse gas emission scenarios designed to cover a wide range of possibilities. 
With such climate change simulations, there are no forecast verifications and only performance statistics for versions run for the twentieth century with quite different forcing. Nevertheless, the producers and consumers of energy can use probabilistic information from the climate change scenarios to examine the relevance and resilience of their business models and strategies. They can prepare now for change that, however unclear, is certain to come.

A mathematical and numerical model of a hypothetical utility, the Virtual Electric Power Company (VEPCO) ${ }^{5}$ illustrates how the strategy of Fig. 12.6 might be implemented. An influence diagram in Fig. 12.7, constructed following Brown (2015), describes a business model that is combined with the evolving probability distributions of temperature, insolation, and precipitation for moderately severe climate change obtained from CMIP5 climate simulations to estimate demand and the availability of solar and hydro power. VEPCO plans an increased reliance on solar and hydro power because of decreasing costs expected for these renewables,

\section{Developing Climate Change Strategies for the Virtual Electric Power Company (VEPCO)}

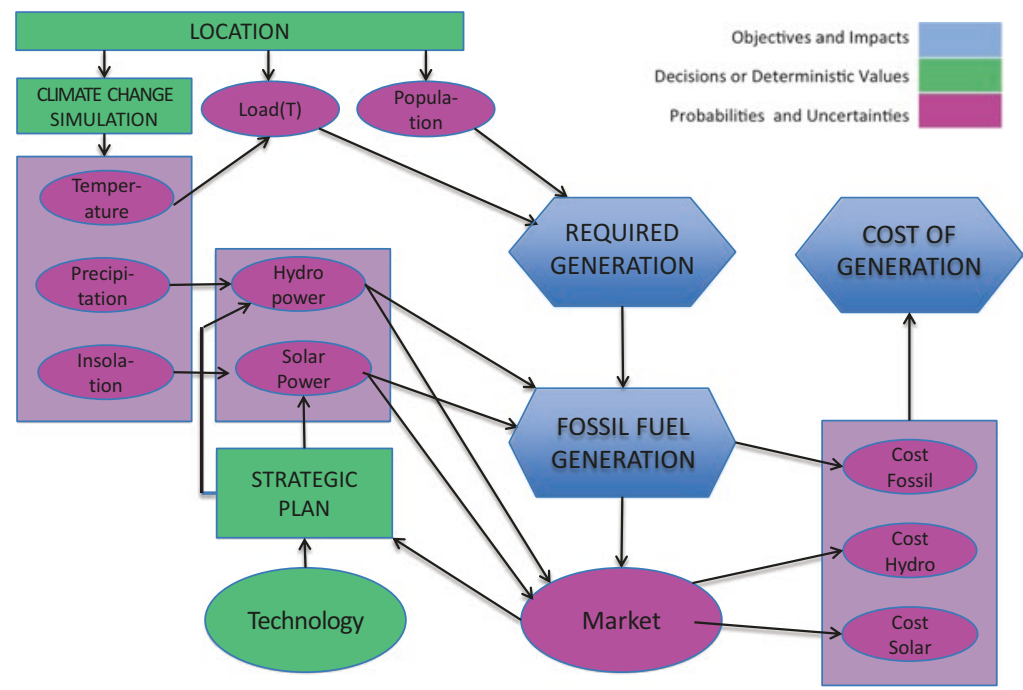

Fig. 12.7 The business model, constructed as an influence diagram, used to generate climate change scenarios for the hypothetical utility VEPCO 


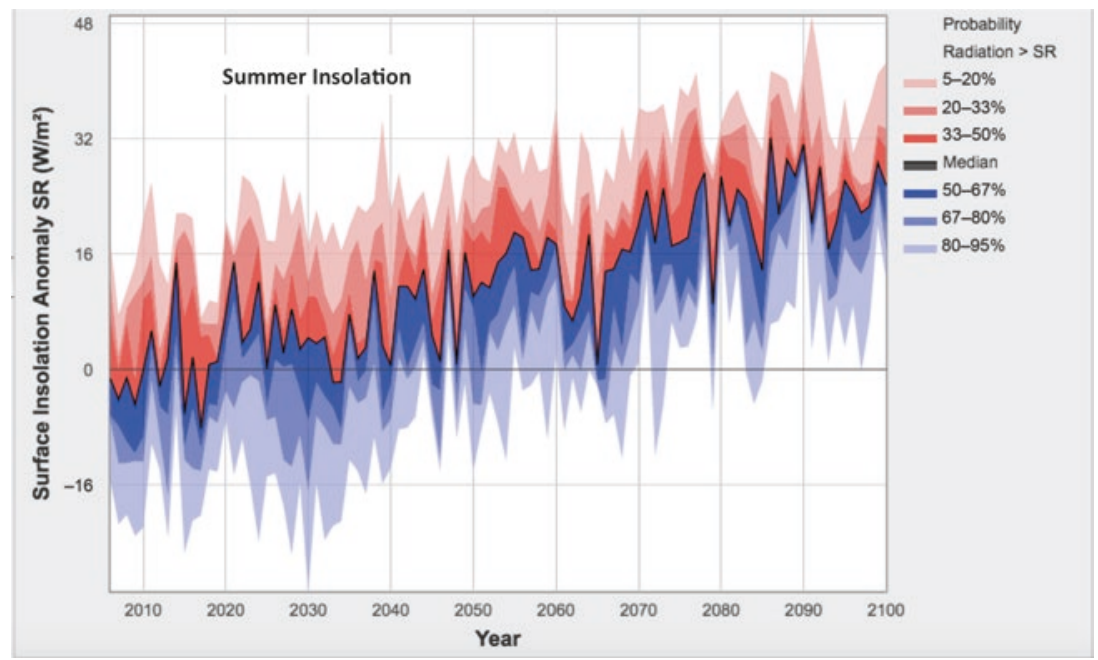

Fig. 12.8 Evolving probability of summer insolation for VEPCO, from one of the IPCC climate simulations for moderately severe climate change $\left(6\right.$ watts $/ \mathrm{m}^{2}$ additional greenhouse heating). The blues are the small-value side of the distribution, the reds the large-value side with the median at the intersection of the two colours

while the cost of fossil power increases. In the simulations, fossil power meets demand remaining after the contribution of hydro and solar power.

As an example of the environmental variables, the evolving probability distributions of insolation obtained from ClimBiz are shown in Fig. 12.8. Suitable probability distributions must be developed for the other variables in Fig. 12.7, including costs of generation, population, and advances in technology. Simulations of VEPCO response to 15 combinations of solar and hydro power for each of the 20-year double decades are shown in Fig. 12.9. And thus VEPCO can choose between minimal expense or minimal volatility or select some combination it expects to be optimum.

The complexity of ensuring resilience is illustrated by this example. Rather than looking at simple statistics, the VEPCO planners can combine the probability distributions that describe several scenarios of climate change from mild-to-severe with distributions describing the potential range of customer needs, technology, policy imperatives, and market 


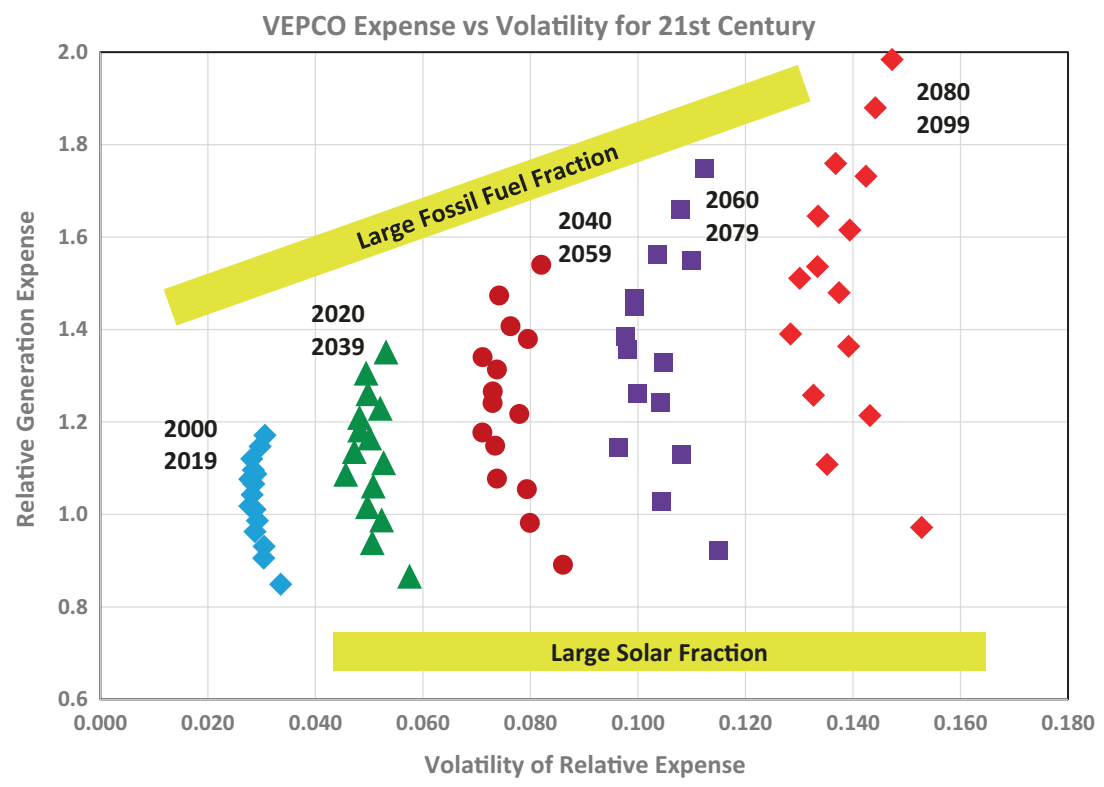

Fig. 12.9 Expense versus volatility relative to present conditions for 15 selections of solar and hydro fractions of generation for five double decades in the twenty-first century, giving VEPCO a range of possibilities for minimizing expense or minimizing volatility. The relative volatility on the $x$-axis is the standard deviation of the relative expense on the $y$-axis

forces as the twenty-first century evolves. Thus, they must combine a comprehensive model of the business and probabilistic models of a variety of forces that may drive change in the business. Sampling from all of these probability distributions will produce an immense amount of data. But all the individual scenarios will combine into smooth probability distributions that depict both likely events in the centre of the distribution and the likelihood in the tails of both adverse and favourable events for which VEPCO must be alert and be prepared to act if necessary.

Being ready for whatever comes is the key benefit of resilience and of examining possible future events through the window of probabilities that describe both their likelihood and uncertainty. As summarized by Hamel and Välikangas (2003): "In a truly resilient organization, there is plenty of excitement ... but no trauma." 


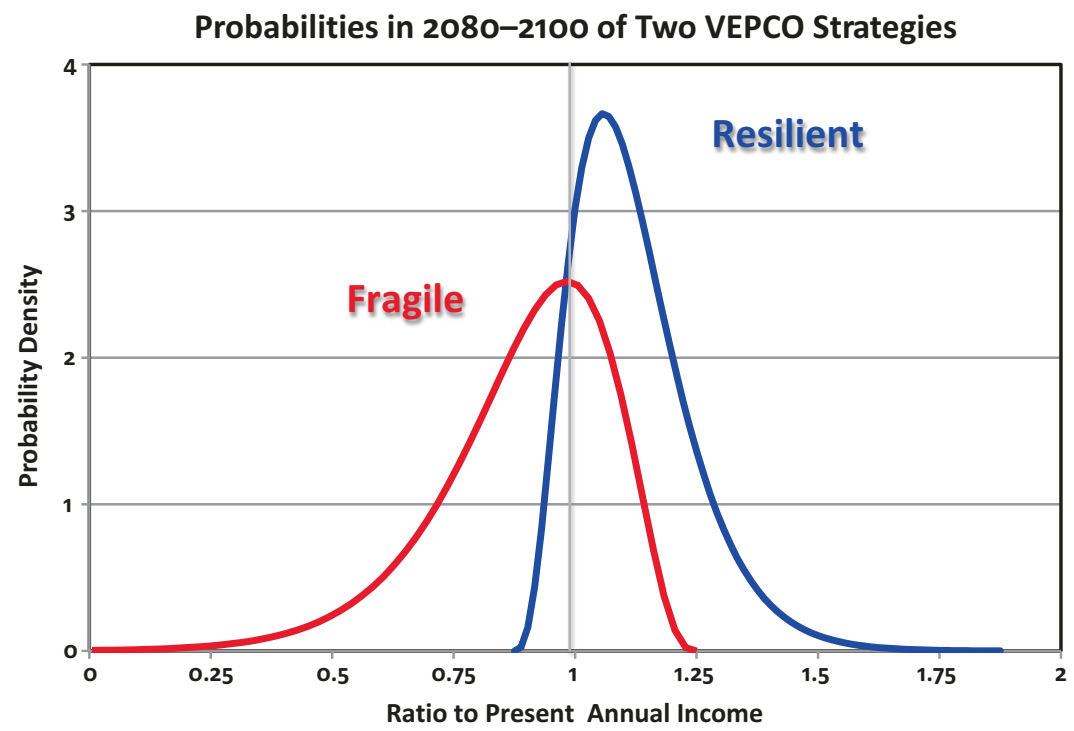

Fig. 12.10 Probability densities associated with VEPCO strategies that would imply favourable or unfavourable prospects for the end of the century. The performance is measured by a ratio of 2080-2100 income to present-day income, both in present-day values. Fragile is used in the sense of vulnerability to volatility (Taleb 2012), resilience for anti-fragile. The resilient density is relatively thin and favours positive income and therefore is robust

Hypothetical probabilities for two different strategies for VEPCO are illustrated in Fig. 12.10, one resilient and one fragile and undesirable. With a business simulation driven by scenarios of climate change and the evolution of economic forces, VEPCO can create probabilistic portraits of its operating variables for the decades to come and identify decisions and action that will ensure resilience. It will be "rehearsing the future", as advocated by Schwartz (1996).

And rehearsing successfully to ensure resilience in the decades ahead will confer the ultimate competitive advantage in the energy and other industries. 


\section{CONCLUSION}

This examination of probability forecasts for energy on timescales ranging from weeks to a century or more has demonstrated that decisions must be two-dimensional and consider both a measure of return or cost and a measure of risk or volatility related to the variance of return or cost, thus echoing the Nobel Prize-winning conclusions of Markowitz (1952) about investment selection.

Hedging adverse forecasts on the S2S scale leads to a range of choices, with maximum return accompanied by maximum volatility compared to minimum volatility with reduced return. Assessment of climate change strategies focused on generation cost produced a similar set of choices for a range of configurations and capital investment commitments for a virtual utility. Finding the pathways to resilience across a variety of potential climate change trajectories thus requires examining a collection of scenarios and then comparing overall return or cost to overall volatility across the full range of potential variation.

Achieving resilience on any timescale has three critical components: forecasts or scenarios for a future period, a model of the business that will yield results as a function of possible hedges or other decisions and actions, and a history or other means of assessing the quality of the forecasts. For S2S forecasts, we created a generic business model and showed how forecast skill functions then produced analytical and numerical comparisons of return and volatility for various predicted probabilities and hedges. For climate variability, the assessment of the expected accuracy and relative value of various climate simulations remains a signal challenge for the climate research community. Until that challenge is met, it seems that the best statistical strategy is to use as many simulations as possible and scale them to a common climatological base over a decade or two. This may produce overly broad probability distributions, but that is preferable to having them too narrow and producing overconfident estimates.

In summary, energy firms can control their statistical future for S2S timescales if sufficiently skilful forecasts are available; for climate change, they can explore a range of statistical futures in search of the pathways to resilience. 
Acknowledgements This chapter is based on Prescient Weather Ltd research supported by the US National Oceanic and Atmospheric Agency with Contracts WC133R-11-CN-0147 and WC-133R-16-CN-0103 and by the US Department of Energy with award DE-SC0011284.

\section{Notes}

1. S2S forecasts are currently available from the US National Weather Service (NWS), Environment Canada, the European Centre for MediumRange Weather Forecasts (ECMWF) and the commercial World Climate Service which combines the NWS and ECMWF forecasts into a multi-model ensemble. The European Copernicus project is offering S2S forecasts from a number of national forecast centres and the NWS is coordinating development of an experimental subseasonal component of the North American Multi-Model Ensemble (NMME). There may be others of which the authors are unaware.

2. We would consider a forecast for rain reliable if it rains on one-third of the days for which we predicted a probability of one-third for rain.

3. A collaborative effort of Prescient Weather in the US and MeteoGroup, a global weather information firm with headquarters in London.

4. This is part of the development by Prescient Weather of a Climate Change Information System for Business and Industry (ClimBiz) sponsored by the US Department of Energy.

5. The virtual VEPCO shares its acronym with the real but unrelated Virginia Electric and Power Company.

\section{REFERENCES}

Brown, R. D. (2015). Business case analysis with R. Retrieved from https://leanpub.com/bizanalysiswithr

Dutton, J. A., James, R. P., \& Ross, J. D. (2013). Calibration and combination of dynamical seasonal forecasts to enhance the value of predicted probabilities for managing risk. Climate Dynamics, 40, 3089-3105.

Dutton, J. A., James, R. P., \& Ross, J. D. (2014). A probabilistic view of weather, climate, and the energy industry. In A. Troccoli, et al. (Eds.), Weather matters for energy (pp. 353-378). New York: Springer.

Dutton, J. A., James, R. P., \& Ross, J. D. (2015). Bridging the gap between subseasonal and seasonal forecasts and decisions to act. AMS Anmual Meeting. Phoenix, AZ. Retrieved January 7, 2015, from https://ams.confel2.com/ ams/95Annual/webprogram/Paper260171.html

Hamel, G., \& Välikangas, L. (2003). The quest for resilience. Harvard Business Review, 81, 52-63. 
James, R. P., Ross, J. D., \& Dutton, J. A. (2014). Skill of a new two- to -six week forecast system. AMS Anmual Meeting. Atlanta. Retrieved February 4, 2014, from https://ams.confel2.com/ams/94Annual/webprogram/Paper233913. html

Markowitz, H. (1952). Portfolio selection. Journal of Finance, 7, 77-91.

National Research Council. (2016). Next generation earth system prediction: strategies for subseasonal to seasonal forecasts. Washington, DC: National Academies Press. 336 pp.

Schwartz, P. (1996). The art of the long view. Reprint with new user's guide. New York: Crown Business. 272 pp.

Taleb, N. N. (2012). Antifragile: Things that gain from disorder. New York: Random House. 519 pp.

Taylor, K. E., Stouffer, R. J., \& Meehl, G. A. (2012). An overview of CMIP5 and the experiment design. Bulletin American Meteorological Society, 93, 485-498.

Vitart, F. (2014). Evolution of ECMWF sub-seasonal forecast skill scores. Quarterly Journal of the Royal Meteorological Society, 140, 1889-1899.

Open Access This chapter is distributed under the terms of the Creative Commons Attribution 4.0 International License (http://creativecommons.org/ licenses/by/4.0/), which permits use, duplication, adaptation, distribution and reproduction in any medium or format, as long as you give appropriate credit to the original author(s) and the source, a link is provided to the Creative Commons license and any changes made are indicated.

The images or other third party material in this chapter are included in the work's Creative Commons license, unless indicated otherwise in the credit line; if such material is not included in the work's Creative Commons license and the respective action is not permitted by statutory regulation, users will need to obtain permission from the license holder to duplicate, adapt or reproduce the material.

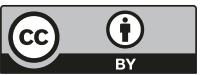

